\title{
Modeling the Killer Whale Orcinus orca via the Lefkovitch Matrix
}

\author{
Ema Carnia $^{* 1}$, Sisilia Sylviani ${ }^{2}$, Melisa Wirmas ${ }^{3}$ and Asep K. Supriatna ${ }^{4}$
}

\begin{abstract}
The Killer Whale Orcinus orca is one of among the protected marine mammals under the Marine Mammal Protection Act (MMPA). It is widely distributed in the world's ocean but its exact status remains unknown, except in few region which is considered as endangered or depleted. Ironically, some hunting activities are still exist in many areas, e.g. as traditional fishery or sport. In this paper we will develop a mathematical model of the whale's population growth via the Lefkovitch matrix. The matrix represent the growth of the population according to certain life stages other than the calendarage, hence it is able to facilitate an overlapping age classes. We will divide the population into the yearling-, juvenile-, reproductive adult,and non-reproductive adult classes. Theoretically the long-term behavior of the growth can be identified by the eigenvalues of the Lefkovitch matrix. In this paper, the model will be parameterized by a published data set. We will also analyze the sensitiveness of the growth parameters, such as the reproduction rate, transition rate and retention rate into the eigenvalues of the model. This will show the most sensitive growth parameters responsible for the destiny of the population. We also give some scenarios of traditional or illegal hunting to the population and its effect on the sustainable growth of the population. The simulation from the data set shows that in the absence of the hunting, the population could grow steadily with growth rate of $2.5 \%$ annually. Sustainable hunting is able to proceed when the target is only aiming to the juveniles class with the rate lower than certain percentage of the population and to the post reproductive classes with the rate lower than certain percentage of the population. Voracious hunting to the productive females certainly would endanger the population.
\end{abstract}

Keywords-Killer Whale mathematical model, Lefkovich matrix, eigenvalue, whale hunting.

\section{INTRODUCTION}

$\mathrm{T}$ HE killer whale (Orcinus orca) is the largest mammal in the world. One issue that attracted the attention of the world community, environmental experts or ordinary people, is the drastically reducing number of the population. To overcome this problem it is required good harvesting policy corresponding to the growth of a population where harvesting is still being done, but do not cause extinction.

In this paper we will discuss population growth model of Orcinus orca and how harvesting may apply. Orcinus orca population growth will be modeled using Lefkovitch matrix

Ema Carnia ${ }^{1}$ is with Department of Mathematics Universitas Padjadjaran Sisilia Sylviani ${ }^{2}$, is with Department of Mathematics Universitas Padjadjaran

Melisa Wirmas ${ }^{3}$, was with Department of Mathematics Universitas Padjadjaran

Asep K. Supriatna ${ }^{4}$, is with Department of Mathematics Universitas Padjadjaran model.

In this model, the population is classified based on the stages of the path that are typically more flexible and allow us to analyze the patterns of more complex life cycle. Lefkovitch matrix can be applied to the population where their age is difficult to 'measured', but but the stage of life they are going through can be seen biologically. For example, the stage of eggs (egg), larva, pupa, or adult (adult) and also in plants would be better if categorized by size [8].

The use of matrix population has also been applied earlier on lionfish populations based on the stage of life in the waters of the Western North Atlantic and Caribbean [6] and in modeling the loggerhead sea turtle population growth [4]. Therefore, in this paper will discuss the matrix Lefkovitch and its implementation in populations of killer whales, Orcinus orca.

\section{II.Population Matrix MODEL}

\section{A. Lefkovitch Matrix}

A matrix model used on the populations that its individual are grouped based on certain conditions, such as the stage of age and the stage of life.

Model matrix that classifies the population by age is Leslie Matrix. Leslie matrix models used in ecology to model the changes in a population an organism over a given period. This model explains the growth of female sex on human and animal populations.

Matrix model that classified the population based on the stage of life is Lefkovitch Matrix. This matrix is a modification of Leslie matrix where the classification replaced by life stage.

The matrix Lefkovitch entries consists the rate of reproduction, survival, and growth in each class. Therefore there will be reproduction parameters (reproductive output) $F_{i}, i=1,2, \ldots, n$, probability of surviving and growing into next stage $G_{i}, i=1,2, \ldots, n-1$, and probability of surviving and remaining in the same stage $P_{i}, i=1,2, \ldots, n$. Thus the general form of Lefkovitch Matrix is 


$$
L=\left[\begin{array}{cccccc}
P_{1} & F_{2} & F_{3} & \cdots & F_{n-1} & F_{n} \\
G_{1} & P_{2} & 0 & \cdots & 0 & 0 \\
0 & G_{2} & P_{3} & \cdots & 0 & 0 \\
\vdots & \vdots & \vdots & & \vdots & \vdots \\
0 & 0 & 0 & \cdots & P_{n-1} & 0 \\
0 & 0 & 0 & \cdots & G_{n-1} & P_{n}
\end{array}\right]
$$

Let $N^{(0)}$ denote population living organisms that $n$ have stages of life ( $n$ classes) where the number of females per class is $x_{1}, x_{2}, \ldots, x_{n}$ when $t=0$ is formed in column matrices, then

$$
N^{(0)}=\left[\begin{array}{c}
x_{1}^{(0)} \\
x_{2}^{(0)} \\
\vdots \\
x_{n}^{(0)}
\end{array}\right]
$$

At $t_{k}$ time the individuals that exist in the first class are individuals who were born in the period between $t_{k-1}$ and $t_{k}$ plus individuals who survive on to the class- 1 at $\left[t_{k-1}, t_{k}\right]$ intervals, which can be expressed in

$$
x_{1}^{(k)}=F_{2} x_{2}^{(k-1)}+F_{3} x_{3}^{(k-1)}+\cdots+F_{n} x_{n}^{(k-1)}+P_{1} x_{1}^{(k-1)}
$$

While individuals in the class- 2 is a first class individuals who growing into the next stage plus individuals who survive and remaining in the same stage, can be expressed by

$$
x_{2}^{(k)}=G_{1} x_{1}^{k-1}+P_{2} x_{2}^{k-1}
$$

We can do the similar way up until the $n$-th equation, therefore we can obtain

$$
\left[\begin{array}{c}
x_{1}^{(k)} \\
x_{2}^{(k)} \\
\vdots \\
x_{n-2}^{(k)} \\
x_{n-1}^{(k)} \\
x_{n}^{(k)}
\end{array}\right]=\left[\begin{array}{cccccc}
P_{1} & F_{2} & F_{3} & \cdots & F_{n-1} & F_{n} \\
G_{1} & P_{2} & 0 & \cdots & 0 & 0 \\
0 & G_{2} & P_{3} & \cdots & 0 & 0 \\
\vdots & \vdots & \vdots & & \vdots & \vdots \\
0 & 0 & 0 & \cdots & P_{n-1} & 0 \\
0 & 0 & 0 & \cdots & G_{n-1} & P_{n}
\end{array}\right]\left[\begin{array}{c}
x_{1}^{(k-1)} \\
x_{2}^{(k-1)} \\
\vdots \\
x_{n-2}^{(k-1)} \\
x_{n-1}^{(k-1)} \\
x_{n}^{(k-1)}
\end{array}\right]
$$

or briefly

$$
N^{(k)}=L N^{(k-1)}=L^{k} N^{(0)}
$$

where $L$ is Lefkovitch Matrix.

\section{B. Population Growth Analysis}

Population growth rate is obtained by finding eigenvalues of matrix growth. Since there will be $n$ eigenvalues, then there is one largest positive/ dominant eigenvalues describing the population change. Suppose the dominant eigenvalues are $\lambda_{m}$, then if

- $\lambda_{m}=1$, population growth is equal to zero or the population is remain the same

- $\lambda_{m}<1$, population growth is negative or the population is decreasing.

- $\lambda_{m}>1$, population growth is positive or the population is increasing

Using $\lambda_{m}$, we can calculate the rate of population growth $(r)$ with

$$
r=\log \left(\lambda_{m}\right)
$$

\section{Sensitivity and Elasticity Analysis}

The Sensitivity and elasticity analysis is important from several perspectives. From the conservation and management perspective, sensitivity analysis can help identify the most contributed parameters to the population growth of a species. The elasticity analysis (proportional sensitivity) is useful in estimating the proportion of changes in the value $\lambda_{m}$ towards parameter change [3]. The sensitivity and elasticity formula are

$$
s_{i j}=\frac{\partial \lambda}{\partial a_{i j}} \text { and } e_{i j}=\frac{s_{i j} a_{i j}}{\lambda_{m}}
$$

where

$s_{i j} \quad$ : Sensitivity value

$\partial \lambda \quad$ : Eigenvalues changes

$\partial a_{i j}$ : Changes in the value matrix entry of the form $F_{i}, G_{i}$, or $P_{i}$ parameter

$e_{i j}:$ Elasticity value

$a_{i j}$ : Changes in the growth matrix entry of the form $F_{i}, G_{i}$, or $P_{i}$

$\lambda_{m}:$ Dominant eigenvalue, and

$$
\sum_{i, j=1}^{n} e_{i j} \cong 1
$$

\section{D.The Harvesting Policy}

A harvesting means eliminating a group of animals from the population. While sustainable harvesting policy is a policy where harvesting is done periodically, but the animal population is not reduced, only the excess growth are eliminated in other words the number of population in the next period will be almost equal to the population in the previous period although harvesting has been done.

If $L$ is a growth matrix and $\mathrm{H}$ is a matrix that contains a fraction of the female population that is harvested $h_{i}$, where $0 \leq h_{i} \leq 1, i=1,2 \ldots, n$ in the form

$$
H=\left[\begin{array}{ccccc}
h_{1} & 0 & 0 & \cdots & 0 \\
0 & h_{2} & 0 & \cdots & 0 \\
0 & 0 & h_{3} & \cdots & 0 \\
\vdots & \vdots & \vdots & & \vdots \\
0 & 0 & 0 & \cdots & h_{n}
\end{array}\right]
$$

then $(L-H)$ is a matrix whose population experiencing harvesting. On sustainable harvesting policy it is expected that total population in the next period is almost equal to the population in the previous period. Even though harvesting has been done or attempted to be constant, then the matrix 
$(L-H)$ must have eigenvalues dominant $\lambda_{m} \cong 1$ so the sustainable harvesting policy that can be applied [1].

\section{METHODS}

The object under study is a population of killer whales Orcinus orca who experienced four stages of life [2].

The data is secondary data obtained from the results of a study published in the Report of the International Whaling Commission, Special Issue 12: 383-405 by Bigg et al in 1990. The study was conducted in the inland waters of Washington and Colombia, precisely northeast section of the Pacific Ocean.

Based on obtained secondary data, first we construct Lefkovitch matrix. Then to see the population growth of Orcinus orca population, we calculate dominant eigenvalues from Lefkovitch matrix. Then we find elasticity value for each parameter and harvesting policies that can be applied by using simulation method.

\section{RESUlTS}

The data used in this paper is the data Orcinus orca killer whale populations is in Table 1 and the value of the parameters in Table 2

TABLE I

DATA OF ORCINUS ORCA POPULATION

\begin{tabular}{|l|l|l|l|l|}
\hline No. & Life stages & $\begin{array}{l}\text { Ages } \\
\text { (years old) }\end{array}$ & $\begin{array}{l}\text { Duration } \\
\text { (year) }\end{array}$ & $\begin{array}{l}\text { Initial } \\
\text { Population }\end{array}$ \\
\hline 1. & Yearlings & $0-9$ & 9 & 15 \\
\hline 2. & Juveniles & $10-34$ & 25 & 50 \\
\hline 3. & Mature females & $35-45$ & 11 & 80 \\
\hline 4. & $\begin{array}{l}\text { Post } \\
\text { reproductive }\end{array}$ & $45-80$ & 35 & 60 \\
\hline
\end{tabular}

Copyright: Bigg, 1990

TABLE II

PARAMETER VALUE DATA OF ORCINUS ORCA POPULATION

\begin{tabular}{|c|c|c|c|}
\hline $\begin{array}{l}\text { Life stages } \\
(i=1,2,3,4)\end{array}$ & $\begin{array}{l}\text { Reproduction } \\
\text { Parameter } / F_{i}\end{array}$ & $\begin{array}{l}\text { Growing } \\
\text { Parameter from } \\
\text { stage } i \text { to } i+1 / G_{i}\end{array}$ & $\begin{array}{l}\text { Surviving } \\
\text { Parameter } \\
\text { stage } i / P_{i}\end{array}$ \\
\hline$i=1$ & & $G_{1}=0.9775$ & \\
\hline$i=2$ & $F_{2}=0.0043$ & $G_{2}=0.0736$ & $P_{2}=0.9111$ \\
\hline$i=3$ & $F_{3}=0.1132$ & $G_{3}=0.0452$ & $P_{3}=0.9534$ \\
\hline$i=4$ & $F_{4}=0$ & & $P_{4}=0.9804$ \\
\hline
\end{tabular}

Copyright: Bigg, 1990

Based on Table 1 and table 2 we can form the life cycle of Orcinus orca, as can be seen in Figure 3.

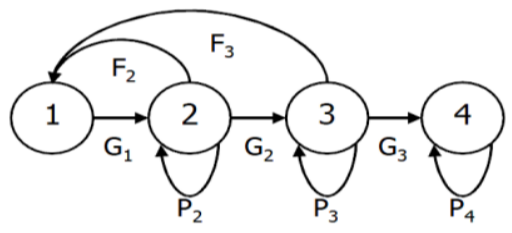

Fig. 3. The life cycle of Orcinus orca

And we can construct Lefkovitch Matrix based on (1)

$$
\begin{aligned}
L & =\left[\begin{array}{cccc}
P_{1} & F_{2} & F_{3} & F_{4} \\
G_{1} & P_{2} & 0 & 0 \\
0 & G_{2} & P_{3} & 0 \\
0 & 0 & G_{3} & P_{4}
\end{array}\right] \\
& =\left[\begin{array}{cccc}
0 & 0.0043 & 0.1132 & 0 \\
0.9775 & 0.9111 & 0 & 0 \\
0 & 0.0736 & 0.9534 & 0 \\
0 & 0 & 0.0452 & 0.9804
\end{array}\right]
\end{aligned}
$$

There exists four Eigenvalue for lefkovitch matrix from (11), that is $\lambda_{1}=0.0048, \lambda_{2}=0.8324, \lambda_{3}=1.0254$, and $\lambda_{4}=0.9804$. Thus the dominant eigenvalues is $\lambda_{m}=\lambda_{3}=$ 1.0254. Since $\lambda_{m}=1.0254>1$ then there is a possibility the population will increase each time where the population growth rate is

$$
r=\log \left(\lambda_{m}\right)=\log (1.0254)=0.0251
$$

which means there will be a population growth of $2.5 \%$

To find the sensitivity value for each parameter $F_{i}, G_{i}$, or $P_{i}$ then made changes in the value of $\alpha$ where $0<\alpha<1$. In this case, choose $\alpha=0.001$ and find the new eigenvalues and $\lambda_{m b}$ henceforth substituted into (5). The sensitivity and elasticity value can also be seen in Table 4.

TABLE IV

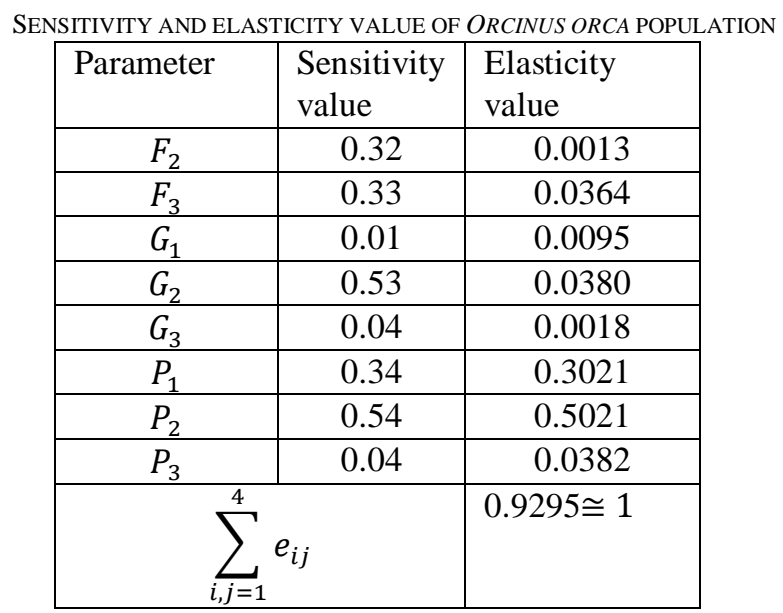

Based on Table 4 we can see that the survival parameters on adult whale $P_{2}$ have the largest elasticity value or, in other words, have the largest proportion on influencing the growth of the population, thus the most influential growth is the second stage on the population of Orcinus orca is the second stage. That is the juveniles and the mature.

Let $h_{i}, i=2,3,4$ a harvesting parameter on Orcinus orca population with initial population $N^{(0)}$ on Table 1 and growth matrix $L$ that is,

$$
N^{(0)}=\left[\begin{array}{l}
15 \\
50 \\
80 \\
60
\end{array}\right]
$$

and 


$$
L=\left[\begin{array}{cccc}
0 & 0.0043 & 0.1132 & 0 \\
0.9775 & 0.9111 & 0 & 0 \\
0 & 0.0736 & 0.9534 & 0 \\
0 & 0 & 0.0452 & 0.9804
\end{array}\right]
$$

where dominant eigenvalue $\lambda_{m}=1.0254$ obtained from the condition of the population has not experienced of harvesting or $h_{2}, h_{3}, h_{4}=0$.

Choose $h_{i}=0.05$ where $i=2,3,4$ that simulated at all possible in stages that exist, which are then searched using the dominant eigenvalue and the value changes in populations over time $N^{(t)}$ using (6). Results of the simulation was obtained $\lambda_{m}$ closest to one is $h_{3}=h_{4}=0.05 ; h_{3}=0$ and $\lambda_{m}=0.9998$.

To get better results $\left(\lambda_{m} \cong 1\right)$ then $h_{3}$ will be simulated where $0<h_{3}<0,05 ; h_{2}=0$ and $h_{4}=0.05$ using maple software.

Based on the second simulation we obtained that are most likely applied to the sustainable harvesting policy is harvesting with the parameter $h_{3}=0.0495, h_{2}=0$ and $h_{4}=0.05$. In other words, harvesting is done by harvesting the $4.95 \%$ of the population of adult whale, $0 \%$ of the juveniles population of adult whale, and $5 \%$ of the population of post reproductive whales that will produce dominant eigenvalue $\lambda_{m}=1.0000$ or population growth is constant based on the number of population or $N^{(t)}$.

\section{V.CONCLUSION}

Based on secondary data analysis we can obtain a model of Orcinus orca population growth with parameter give in

$$
L=\left[\begin{array}{cccc}
0 & 0,0043 & 0,1132 & 0 \\
0,9775 & 0,9111 & 0 & 0 \\
0 & 0,0736 & 0,9534 & 0 \\
0 & 0 & 0,0452 & 0,9804
\end{array}\right]
$$

We obtained population growth rate amounted to 0.0251 or there exists population growth of $2.5 \%$ annually. Based on the elasticity value we can conclude that the stages of growth that is very influential on Orcinus orca whale population is the second step, that young adult whale (juveniles) and the third stage is the mature. Using simulation to harvest a maximum of $5 \%$ population, sustainable harvesting policy that might be done is to harvest $0 \%$ of the population of juveniles, $4.95 \%$ mature and $5 \%$ of the post reproductive population, will produce a constant population growth. The weakness of the model is that it is growing exponentially. A density-dependent model is investigated.

\section{ACKNOWLEDGMENT}

This work is funded by the ALG (Academic Leadership Grant) of Universitas Padjadjaran.

\section{REFERENCES}

[1] Anton, Howard. 2005. Elementary Linear Algebra Application Version/Eighth Edition. John \& Wiley Sons, Inc

[2] Bigg, M. A., P. F. Olesiuk, G. M. Ellis, J. K. B. Ford, and K. C. Balcomb. 1990. Social organizations and genealogy of resident killer whales (Orcinus orca) in the coastal waters of British Columbia and Washington State. Report of the International Whaling Commission, Special Issue 12:383-405

[3] Caswell, H. 2001. Matrix Population Models: Construction, Analysis and Interpretation, Second Edition. Sunderland : Sinauer Associates, Inc

[4] Crouse DT, Crowder LB, Caswell H. 1987. A stage-based population model for loggerhead sea turtles and implications for conservation. Ecology 68:1412-1423 http://dx.doi.org/10.2307/1939225

[5] Lefkovitch, LP. 1965. The Study of Population Growth in Organisms Grouped by Stages. Biometrika 35: 183-212 http://dx.doi.org/10.2307/2528348

[6] Morris, J.A. Jr. dan P.E. Whitfield. 2009. Biology, ecology, control and management of the Invasive Indo-Pacific lionfish: An updated Integrated Assessment. NOAA Technical Memorandum NOS NCCOS 99. $57 \mathrm{pp}$.

[7] Sun L and Wang M. 2007. An algorithm for a decomposititon of weighted digraphs: with applications to life cycle analysis in Ecology. Math Biology 54: hal. 199-226.

[8] Yusoff, Nuraini. Budin, Harun dan Ismail, Salemah. 2012. Simulation of Population Dynamics of Aedes aegypti using Climate Dependent Model. International Journal of Medical and Biological Sciences, 6: 97-102. 